\title{
A REESTRUTURAÇÃO NA EDUCAÇÃO BÁSICA E OS IMPACTOS NO TRABALHO DOCENTE EM PATOS DE MINAS/MG
}

\author{
RESTRUCTURING IN BASIC EDUCATION AND IMPACTS IN TEACHING WORK IN \\ PATOS OF MINAS/MG
}

\author{
R. M. MACIEL ${ }^{1, *}$, F S PREVITALI $^{1}$ \\ ${ }^{1}$ Universidade Federal de Uberlândia, Programa de Pós-Graduação em Educação, Brasil
}

\author{
ARTICLE INFO \\ Article history: \\ Received 2018-07-02 \\ Accepted 2018-08-17 \\ Available online 2018-08-31 \\ *Autor correspondente: \\ E-mail: macielrosana28@hotmail.com
}

Palavras-chave: Educação básica. Trabalho docente.

Reestruturação Produtiva.

Keywords: Basic education. Teaching work.

Productive Restructuring.

RESUMO. O presente trabalho consiste na concretização de uma pesquisa de Mestrado, pertencente ao Programa de Pós-Graduação Stricto Sensu em Educação da Universidade Federal de Uberlândia, na linha de pesquisa intitulada "Políticas e Gestão em Educação". Trata-se do trabalho realizado através de leituras, debates e reflexões desenvolvidas no Grupo de Pesquisa Trabalho, Educação e Sociedade - GPTES e conta com o apoio da Coordenação de Aperfeiçoamento de Pessoal de Nível Superior - CAPES. O estudo discute a reestruturação produtiva na esfera educacional e seus impactos no trabalho docente da rede pública estadual de Minas Gerais, a partir de 1990 quando se intensificam as reformas educacionais no Brasil, particularmente em Patos de Minas - MG. Mais especificamente visa discutir os processos de proletarização e precarização do trabalho docente no que se refere à intensificação do trabalho, condições de trabalho e controle sobre o processo de trabalho; contextualizar e reestruturação da educação e do trabalho docente no cenário de mundialização do capital, especialmente no âmbito nacional, face às reformas educacionais dos anos 1990 . Tais reflexões estão fundamentadas em uma pesquisa empírica, realizada no município de Patos de Minas/MG. A pesquisa foi desenvolvida através da discussão teórica acerca da articulação dialética entre educação e trabalho, demonstrando também as modificações ocorridas com o processo de reestruturação produtiva.

ABSTRACT. The present work consists in the accomplishment of a Master's research, belonging to the Stricto Sensu Post-Graduation Program in Education of the Federal University of Uberlândia, in the line of research entitled "Policies and Management in Education". This is the work done through readings, debates and reflections developed in the Group of Research Work, Education and Society - GPTES and counts on the support of the Coordination of Improvement of Higher Level Personnel - CAPES. The study discusses the productive restructuring in the educational sphere and its impact on the teaching work of the state public network of Minas Gerais, from 1990 onwards when educational reforms in Brazil intensify, particularly in Patos de Minas - MG. More specifically, it aims to discuss the processes of proletarianization and precariousness of teaching work in relation to the intensification of work, working conditions and control over the work process; contextualize and restructure education and teaching work in the context of the globalization of capital, especially at the national level, in the face of the educational reforms of the 1990s. These reflections are based on an empirical research carried out in the municipality of Patos de Minas / MG. The research was developed through the theoretical discussion about the dialectical articulation between education and work, also showing the changes that occurred with the process of productive restructuring. 


\section{Introdução}

O presente estudo insere-se no âmbito das investigações sobre políticas e gestão em Educação e tem como temática a reestruturação produtiva na Educação, particularmente as reformas educacionais na educação básica a partir da década de 1990 e seus impactos sobre o trabalho docente na rede estadual de Patos de Minas - MG.

O objetivo geral desse trabalho é analisar a reestruturação produtiva, particularmente as reformas educacionais e seus impactos no trabalho docente da rede pública estadual de Minas Gerais, a partir de 1990 quando se intensificam as reformas educacionais no Brasil e em Minas Gerais.

Realizou-se uma pesquisa empírica sobre a temática junto ao Sindicato Único dos Trabalhadores em Educação - Sind-UTE da cidade de Patos de Minas/MG. Foram realizadas entrevistas com três membros da diretoria do sindicato no $2^{\circ}$ semestre de 2011.

O estudo bibliográfico envolveu a discussão sobre a temática do capitalismo, inserida no conceito histórico da reestruturação produtiva do mundo do trabalho frente à reconfiguração do cenário político mundial. Analisou-se os periódicos de maior relevância na área em articulação com a atual literatura referente à temática abordada, com fundamentos tanto no pensamento clássico ou interpretações do desenvolvimento brasileiro (Ricardo Antunes, Karl Marx, Harry Braverman, François Chesnais, João Bernardo, entre outros).

Por fim, foram realizadas entrevistas com três membros da diretoria do Sindicato Único dos Trabalhadores em Educação de Minas Gerais - SindUTE/MG na cidade de Patos de Minas para análise comparativa entre a literatura existente sobre a temática e o discurso do SindUTE/MG.

As entrevistas foram norteadas por questões fechadas e semi-abertas, de forma a compreender-se como o sindicato que representa os professores da rede estadual, analisa a reestruturação produtiva na educação e seus impactos no trabalho docente, bem como de sua função política em relação a esse processo. Foram analisados também, documentos fornecidos pelo sindicato.

De posse dos referenciais teóricos e documentos legais, foi realizado um confronto e análise de todos os dados encontrados no desenvolvimento da pesquisa.

Para a análise das entrevistas semi-estruturadas, foi verificada a frequência das respostas apresentadas, bem como uma análise crítica do conteúdo dessas respostas. As perguntas das entrevistas destinadas aos membros do Sindi-UTE foram construídas objetivando fornecer um diagnóstico da situação vivenciada pelos professores frente às políticas públicas de caráter neoliberal em âmbito nacional e estadual. 


\section{FUNDAMENTAÇÃO}

\section{As reformas educacionais em Minas Gerais}

Inserido nesse contexto de reformas educacionais, o estado de Minas Gerais teve sua primeira iniciativa dentro de um discurso da modernização, denominado por Marques (2000) de "tempo da democratização". Nesse período, no governo de Hélio Garcia (1984-1986) o trabalho docente foi levado a uma condição de polivalência, no sentido de se responsabilizar por qualquer conteúdo ou disciplina que fosse necessário. Juntamente com essa medida foi criada a gratificação de incentivo à docência e a progressão horizontal. Essas medidas foram tomadas para reduzir o número de funcionários na Secretaria de Educação. (MARQUES, 2000)

Em continuidade a esse processo, no governo de Newton Cardoso, em 1987, ocorreu o período denominado por Marques (2000) de "modernização e racionalização do Estado", com redução de gasto com recursos humanos na área educacional e, consequentemente, um aumento do trabalho do profissional da educação, que passou a acumular tarefas. (MARQUES, 2000).

Com o compromisso de universalizar o ensino fundamental, os estados brasileiros depararam-se com um novo problema: o aumento significativo do número de alunos nas escolas e a falta de qualidade de ensino para atender a essa nova demanda. Esse fator desencadeou aumento da evasão e repetência escolar.

O governo de Minas Gerais, sob comando de Hélio Garcia (1991-1994), desenvolveu reformas voltadas para conceitos neoliberais em que a crise educacional era causada por fatores gerenciais. Nasceu assim, através dos programas de qualidade total implementados nas empresas no âmbito da difusão do toyotismo, a Gerência da Qualidade Total da Educação e o ProQualidade, com características de reorganização do sistema escolar mineiro. Ocorre aí o período denominado "tempo da qualidade total na educação". (MARQUES, 2000)

Esses programas acompanharam as tendências mundiais e nacionais, nas quais a palavra de ordem passa a ser a flexibilidade. Nesse contexto, esses programas voltados para adoção de uma abordagem mais sistêmica do toyotismo passa a atuar no fortalecimento da autonomia dos professores e direção escolar - que na verdade possui um caráter de aumento das responsabilidades para as escolas, capacitação de professores, avaliação de desempenho e municipalização. (AUGUSTO; MELO, 2004)

O mandato de Itamar Franco, como Governador de Minas Gerais (1999-2003), foi marcado por forte oposição ao governo federal, assumido por Fernando Henrique Cardoso. Esse período foi denominado de "tempo da modernização arcaica" (MARQUES, 2000). A reforma educacional mineira nesse período teve como principal foco a criação da "Escola Sagarana: educação para a vida com dignidade e esperança", que visava garantir o acesso 
ao ensino de qualidade para todos, valorização dos profissionais da educação, interrupção dos processos de municipalização da educação no estado. (MARQUES, 2000).

Augusto e Melo (2004) ressaltam que tanto no governo de Hélio Garcia, como no de Itamar Franco ocorreu um processo de intensificação e precarização do trabalho docente. Os fatores que demonstram tal afirmativa são: economia voltada para redução de gastos, redução do quadro de funcionários, aumento das obrigações dos professores e aumento da jornada de trabalho não acompanhada da correspondência salarial, prevista legalmente desde a Constituição Federal de 1988 (art. 206).

Na sucessão de Itamar Franco, Aécio Neves (2003 - 2006) direcionou sua reforma administrativa pela aplicação do chamado "Choque de Gestão", que apresentava como foco principal solucionar os problemas financeiros e resgatar a modernização do estado de Minas Gerais no contexto nacional e mundial. (VILHENA et al., 2006).

Dentre os planos desenvolvidos no "Choque de Gestão", foram criados novos Planos de Carreira para os servidores públicos estaduais. Esses planos começaram a ser aplicados no ano de 2005, com enfoque no desenvolvimento da carreira e o processo de Avaliação Individual de Desempenho - ADI, com o objetivo de aumentar a eficiência da administração pública. (MINAS GERAIS, Lei Complementar n.71/03)

A ADI possui validade anual, sendo o funcionário público avaliado de $1^{\circ}$ de janeiro a 31 de dezembro (MINAS GERAIS, Decreto n. 44.559/07, Art. $3^{\circ}$ ), tendo como critérios de avaliação e acompanhamento do servidor a pontualidade, produtividade, qualidade de trabalho, assiduidade, aproveitamento em cursos de capacitação, capacidade de trabalho em equipe e administração do tempo (MINAS GERAIS, Decreto n.44.559/07, Art. $2^{\circ}$ ). Alves (2006) acredita que a ADI é um instrumento de controle avaliativo dos servidores públicos, no enfoque da administração gerencial. No governo Aécio Neves o estado assume uma tendência de racionalização e modernização administrativa, com a implementação do Choque de Gestão.

\section{As condições de trabalho dos professores sob a ótica da Secretaria Estadual de Educação de Minas Gerais - SEE/MG}

O processo de trabalho docente deve ser entendido como uma relação entre classes sociais distintas e opostas, dentro do sistema capitalista. (SANTOS, 2005). A organização do processo de trabalho dos professores da SEE/MG é estabelecida pela relação existente entre - Estado e trabalhadores docentes. O formato de sua organização é específica do sistema econômico-social hegemônico. A lógica da produtividade embasa as medidas em implementação no Estado, nas relações de trabalho.

Para entender a definição do que são condições de trabalho, é necessário apresentar os conceitos de organização escolar e organização do trabalho escolar. 
Segundo Oliveira (2002) organização escolar refere-se, à maneira como o ensino está estruturado: formas de avaliação, currículos, procedimentos didáticos, programas de ensino, metodologia, distribuição de conteúdos pela carga horária e calendários escolares.

Com relação a organização do trabalho escolar, diz respeito, segundo a autora, à divisão do trabalho na escola, à maneira como o trabalho e os trabalhadores estão organizados. Competência, horário de trabalho, atribuição de funções, tarefas, competências, relações de hierarquia, entre outros. O conceito de organização do trabalho escolar auxilia na compreensão das relações sociais de trabalho, e segundo a autora:

(...) deve ser compreendido à luz das teorias econômicas. Compreende uma forma específica de organização do trabalho sob o capitalismo. No processo de trabalho capitalista, os insumos, objetos e meios de trabalho, estão submetidos a uma orientação bastante específica, que é a finalidade da produção sob o signo do capital. (OLIVEIRA, 2002, p.18)

As condições de trabalho são definidas pela autora como a maneira como está organizado o processo de trabalho do professor: jornadas de trabalho, avaliação de desempenho, horários, procedimentos didático-pedagógicos, admissão e administração das carreiras docentes, condições materiais de trabalho e relação salário e tempo de trabalho. "A divisão social do trabalho, as formas de regulação, controles e autonomia no trabalho, estruturação das atividades escolares, relação de número de alunos por professor, também estão compreendidos no conceito condições de trabalho". (OLIVEIRA, 2002, p.24)

$\mathrm{Na}$ SEE/MG tem ocorrido reestruturação do trabalho dos professores, interligando esse trabalho a resultados mensuráveis, associados à avaliação de desempenho, processo que promove inquietação e tensão no ambiente de trabalho.

Os professores apresentam três situações funcionais: efetivos, efetivados e designados. Os efetivos são concursados nomeados, os efetivados são os professores contemplados pela Lei Complementar no 100/2007, na qual os professores efetivados permaneceram nos cargos com vantagens e desvantagens e, por não passarem em concurso público de provas e títulos ficaram a mercê do governador e os professores designados que são os contratados temporários, que devem concorrer anualmente às vagas remanescentes, no início do ano letivo. O controle das designações é feito pelas Superintendências Regionais de Ensino.

A quantidade de servidores das escolas está diretamente relacionada ao número de alunos e ao espaço físico e prevalece sempre a baixa proporção entre o quadro de pessoal em relação às necessidades reais. O número de alunos por turma é definido pelo sistema central, fixado, há muitos anos, em 30 alunos nas primeiras séries do ensino fundamental, 35 alunos nas últimas séries e em 40 alunos no ensino médio, no mínimo. 
Existem mecanismos de controle na forma de organização executada pelo Estado sobre o gerenciamento de pessoas e escolas em seu sistema educacional. Esses mecanismos são constituídos por critérios na avaliação do desempenho institucional e individual. Os resultados das avaliações determinam os salários, as progressões na carreira e formas de intervenção para redirecionar as ações, e até a possibilidade de dispensa de pessoal.

$\mathrm{Na}$ organização escolar na SEE/MG, o conhecimento é estruturado em disciplinas isoladas que compõem as grades curriculares. Os docentes apresentam jornada semanal de trabalho de 18 aulas, de 50 minutos cada aula e 5 aulas de planejamento das atividades pedagógicas. Arroyo (2000) define que a concepção de organização escolar, que estrutura o conhecimento por áreas isoladas e disciplinas isoladas apresentam como consequência a fragmentação curricular.

As medidas empreendidas desde o Governo de Aécio Neves sobre a reforma do Estado, denominada "Choque de Gestão", em relação aos servidores públicos, e justificadas como saneamento das contas públicas, cumprimento da Lei de Responsabilidade Fiscal, modernização e melhoria da qualidade dos serviços públicos, podem ser assim resumidas, segundo Augusto (2004):

- substituição do critério de tempo de serviço para concessão de benefícios (biênios, quinquênios, férias - prêmio), pelo desempenho profissional. Ganho adicional por avaliação de desempenho;

- criação de Adicional de Desempenho - ADE, que estabelece novo modelo de remuneração: "recebe mais quem produz mais e melhor"1;

- possibilidade de demissão por insuficiência de desempenho;

- possibilidade de demissão por insuficiência de receita estadual;

- plano de carreira, prevendo tais medidas, vigente a partir de agosto de 2004, mas ainda em implementação, que estabelece a certificação profissional;

- vinculação entre arrecadação do ICMS e reajustes salariais, atrelando os percentuais de aumento. (AUGUSTO, 2004, p.50)

O Estado de Minas Gerais passou pelo processo de reestruturação produtiva dos anos 1990, através de modificações na legislação e na postura política voltadas para a educação.

\footnotetext{
${ }^{1}$ Documento emitido pelo Governo Estadual: Reforma do Estado - Minas fazendo o que tem que ser feito. Julho de 2003.
} 


\section{O olhar do sindicato dos trabalhadores da educação de minas gerais- SINDUTE sobre o trabalho docente}

\section{Informações gerais sobre o SINDUTE - Patos de Minas}

O SindUTE subsede Patos de Minas foi escolhido para a pesquisa por ser o sindicato responsável pelos professores da rede estadual de ensino de Patos de Minas.

Foram realizadas entrevistas com três membros da diretoria do SindUTE/MG na cidade de Patos de Minas para análise comparativa entre a literatura existente sobre a temática, o discurso e a prática do SindUTE/MG.

As entrevistas foram realizadas com três membros da diretoria do Sindicato, denominadas de Entrevistada A, Entrevistada B e Entrevistada C.

O sindUTE Patos de Minas está localizado no centro da cidade de Patos de Minas, a Rua Major Gote, número 1022. Segundo as entrevistadas o sindicato surgiu da demanda dos professores de Patos de Minas e região, no ano de 1979 fundado pelo professor Salvador Rodrigues e pela professora Celina Gonçalves, conforme comprovado no documento oficial do sindicato.

Atualmente a diretoria do sindicato é composta por 12 membros, escolhidos através de eleição realizada pelos professores efetivos filiados, com mandato de 3 anos. Todos os membros da diretoria são servidores públicos estaduais da educação.

De acordo com a Entrevistada A, o sindicato em Patos de Minas atende a 32 municípios através da demanda dos professores do Estado e não há nenhuma escola municipal filiada a este sindicato. Atualmente, o sindicato possui aproximadamente 1.700 filiados considerando todos os municípios atendidos. No entanto, não forneceu nenhum documento que comprovasse essa informação. De acordo com a folha de recebimento, Patos de Minas conta com 937 filiados. $^{2}$

De acordo com a Entrevistada $B$ houve um decréscimo do número de filiados provocado pela filiação dos professores à Associação de Professores Públicos de Minas Gerais - PPMG.

De acordo com as entrevistadas houve grandes mudanças no perfil dos filiados ao sindicato depois das reformas educacionais dos anos 1990, principalmente no que diz respeito à motivação nas lutas pelos direitos. Essa desmotivação deve-se, segundo as entrevistadas à necessidade que os professores têm de trabalhar em mais de uma escola para conseguir um salário digno. Outra característica que provocou essa desmotivação foi a mudança das

${ }^{2}$ Dados extraídos da folha de recebimento do SindUte-Patos de Minas do mês de julho de 2011. 
características dos alunos. Segundo as entrevistadas, as famílias passaram a responsabilidade de educar os filhos para a escola.

As entrevistadas A e B acreditam que a quantidade de escolas estaduais no município de Patos de Minas atende à demanda da população estudantil pois segundo elas, não existe reclamação para o sindicato, quanto à falta de vagas para os alunos em idade escolar. No entanto, as entrevistadas ressaltam a necessidade de uma melhor distribuição geográfica das escolas e que a Superintendência Regional de Ensino de Patos de Minas está atenta a essa necessidade, e já existem projetos de construção de mais escolas nos bairros que necessitam.

\section{A natureza do trabalho docente em Minas Gerais}

Buscou-se com a entrevista compreender a representação dos sujeitos entrevistados sobre a natureza do trabalho docente antes e depois das reformas educacionais dos anos 1990. As entrevistadas colocaram que os professores ainda têm vontade de ensinar, de fazer o trabalho bem feito, mas, pela necessidade de lecionar em mais de uma escola, falta tempo para executar suas tarefas de planejamento. De acordo com a Entrevistada $A$, há a questão da indisciplina, da sobrecarga de trabalho e da falta de material didático, mas ela chama atenção principalmente para a desmotivação profissional.

Sobre as mudanças no perfil do professor dos anos 1990 e dos professores nos dias atuais, as entrevistadas afirmam que houve grande redução no nível de reconhecimento profissional por parte do Estado, e também que a formação acadêmica era melhor estruturada antes nos anos 1990.

Os problemas de indisciplina, problema de desmotivação do profissional, né? Falta de reconhecimento... Isso é uma coisa do Estado inteiro. A precariedade nas escolas, falta de material, excesso, sobrecarga de trabalho. Então, eu acho que... que fica trabalhando dois, três turnos, né? Pra sobreviver... Então eu acho que é uma coisa generalizada, né? No Estado inteiro. Eu acho que é no Brasil, infelizmente. (Entrevista realizada com a Entrevistada B, em 08/10/11)

De acordo com a SEE/MG (2011), a caracterização do trabalho docente em Minas Gerais, a contratação dos professores passa por 3 categorias: professores efetivos, efetivados e designados. Os professores efetivos são os que entraram no Estado através de concurso público, o professor designado, entrou no Estado através da LC $n^{\circ} 100$, que amparou 0 professor efetivado, garantido seu cargo no Estado por tempo indeterminado e o professor designado, que trabalha com as vagas remanescentes das escolas e com contrato por tempo previamente estabelecido. A Entrevistada A afirma que:

O efetivo é o concursado, né? O efetivado foi o que o governo criou uma lei, inconstitucional, a lei 100, e a pessoa ta ai até hoje 
sem fazer um concurso, sem nada. E... e... quando acontece de vir um concursado de outra região ou de outra escola, onde tá o efetivado, o efetivado perde o lugar pra aquele concursado. Então é completamente diferente. O concursado ele tem estabilidade. Agora o efetivado não. .(Entrevista realizada com a Entrevistada A, em 29/06/2011)

O SindUTE Patos de Minas defende como forma legal de contratação dos professores o concurso público, por ser um direito garantido por lei. Segundo a Entrevistada A:

Não. A gente não concorda porque primeiro porque ela é inconstitucional. A gente não defende... a gente defende a legalidade, né? Ela fere a Constituição Federal, a lei 100. Mas, a gente não... a gente não acha que isso é um meio de estabilizar. Deveria ter concurso pras pessoas fazer o concurso pra poder estabilizar, né? E não através de leis... criadas... .(Entrevista realizada com a Entrevistada A, em 29/06/2011)

Ele ( o governo) implantou essa lei 100 pra resolver um problema financeiro dele e político, com o governo federal. Se ele não implementasse a lei 100, se ele não criasse a lei 100, ele teria que passar uma verba muito grande pro governo federal. Como a verba já estava impagável, aliás, os valores que ele devia pro governo federal estava impagável, né? Eram valores muito altos. Ele criou a lei 100 pra resolver o problema, senão ele não recebia verba pro Estado, e ele não repassava também a contribuição do servidor, que deveria ser passada pra união, ele não repassada há anos e anos. Então a dívida já estava impagável. Ele criou essa lei 100 pra resolver um problema dele. E não do servidor. Do governo de Minas, né? Do governo anterior que é o mesmo que tá ai, com o vice dele, né? .(Entrevista realizada com a Entrevistada A, em 29/06/2011)

O sindicato afirma que a LC n¹00 fere a Constituição Federal de 1988 que define que a contratação de funcionário público deve ser realizada através de concurso público e coloca os motivos da implantação dessa LC. Portanto, o sindicato posiciona-se contrário à LC n 100.

\section{O processo de reestruturação produtiva na educação em Minas Gerais: a visão do sindicato}

Buscou-se nas entrevistas, verificar como o SindUTE Patos de Minas percebe o processo de reestruturação produtiva no qual a esfera educacional está inserida. Percebeuse que o sindicato acompanha esse processo e coloca as reformas administrativas como foco dessa reestruturação. 
A função do sindicato no contexto da reestruturação produtiva da educação é de conscientizar e manter o quadro docente informado sobre as mudanças que ocorrem na esfera governamental.

As entrevistadas acreditam que a reestruturação produtiva que ocorreu a partir das reformas educacionais dos anos 1990 foi prejudicial para a classe docente, pois modificou várias características do trabalhador docente. Entre essas mudanças foi citado o perfil do professor - que devido aos contratos temporários perde o comprometimento com as lutas de classe e a falta de capacitação profissional.

Foram apontadas como principais consequências da reestruturação produtiva para os professores: desemprego, redução do número de sindicalizados, perdas salariais, mudanças nas formas de lutas e reivindicações, aumento da quantidade de alunos por sala.

As entrevistadas acreditam que o sindicato busca participar de forma efetiva no processo de reestruturação produtiva, através de reivindicações, propostas de projetos, porém colocam que não obtêm o resultado esperado junto ao governo do Estado de Minas Gerais.

Quanto ao questionamento sobre os impactos da reestruturação produtiva na educação em Minas Gerais, percebeu-se que os maiores impactos com relação aos professores foram a desvalorização salarial, as mudanças, desmotivação e falta de capacitação profissional.

Percebe-se que a perda salarial foi o maior impacto causado pelo processo de reestruturação produtiva na educação em Minas Gerais, segundo a visão do sindicato.

\section{Sobre os processos de precarização e intensificação do trabalho docente}

Para ter conhecimento sobre os processos de precarização que os professores passam, foram abordadas questões sobre essa temática.

As entrevistadas definem precarização do trabalho docente como redução dos direitos dos professores e aumento das suas obrigações dentro e fora da sala de aula - atuando, às vezes, em funções que não são características da profissão docente. Nas palavras da Entrevistada B:

(...) a precarização do trabalho docente ele ta no salário, né? Que tá bem inferior aquilo que a gente espera e merece. Nas condições de trabalho, né principalmente na falta de profissionais que atuar dentro das escolas hoje, né, psicólogos, assistentes sociais, disciplinários, pessoas com o olhar voltado para o ser humano, né? Eu acho que a precarização hoje ela vai mais nesse lado, da... da... do ser humano. A falta de capacitação, né?, a falta de treinamentos não só para os professores, para o corpo docente, não, mas para todos os 
funcionários, né. Essa falta de formação no atendimento, né? A gente vê isso como algo muito precário na educação, né? (Entrevista realizada com a Entrevistada B, 08/10/11)

Outro fator apontado quanto à precarização foi a política salarial implementada desde o governo de Aécio Neves (2002 -2010). A Entrevistada A coloca que o sindicato está lutando por um piso salarial nacional, que está na Constituição Federal de 1988, e ainda não foi implementado em Minas Gerais.

A Lei Federal $\mathrm{n}^{\circ} 11738$ de 16 de julho de 2008 estabelece o piso salarial nacional no valor de $\mathrm{R} \$ 1.187,14$ e define que

Esta Lei regulamenta o piso salarial profissional nacional para os profissionais do magistério público da educação básica a que se refere a alínea "e" do inciso III do caput do art. 60 do Ato das Disposições Constitucionais Transitórias.(LEI 11.738, de 16/07/2008, art. $1^{\circ}$ )

Atualmente, em Minas Gerais, no governo de Antônio Anastasia (2011-) foi adotada uma nova política remuneratória para as carreiras dos servidores da Educação: é o sistema de remuneração de pagamento por subsídio. Nesse tipo de remuneração, todas as vantagens são incorporadas ao valor total pago, não existindo plano de carreira, conforme mostra $\mathrm{o}$ artigo $2^{\circ}$ da Lei 11.738 :

Art. $2^{\circ}$. No valor do subsídio de que trata esta Lei estão incorporadas as parcelas do regime remuneratório anterior abaixo especificadas, atribuídas às seguintes carreiras:

II - Especialista em Educação Básica:

a) vencimento básico ou provento básico;

b) gratificação de função a que se refere 0 art. $7^{0}$ da Lei $n^{0}$ 11.091, de 4 de maio de 1993;

c) gratificação de educação especial prevista no art. 169 da Lei o 7.109 , de 1977;

d) gratificação por curso de pós-graduação prevista no parágrafo único do art. 151 da Lei no 7.109, de 1977;

e) gratificação por regime especial de trabalho prevista no art. 145 da Lei no 7.109, de 1977, e no art. 72 da Lei no 11.050, de 1993. .(LEl 11.738, de 16/07/2008, art.2)

Parágrafo único. Além das parcelas previstas no caput, o subsídio de que trata esta Lei incorpora as demais vantagens pecuniárias a que fizer jus o servidor, em especial:

$\mathrm{I}$ - adicionais por tempo de serviço previstos nos arts. 112 e 113 do Ato das Disposições Constitucionais Transitórias - ADCT - da Constituição do Estado;

II - vantagem pessoal prevista no $\S 3^{\circ}$. do art. $1^{\circ}$ da Lei $n^{\circ}$ 10.470 , de 15 de abril de 1991, e no art. 1ㅇ da Lei no 13.694 , de $11^{\circ}$ de setembro de 2000; 
III - auxílio-alimentação previsto no Decreto nำ37.283, de 3 de outubro de 1995;

IV - adicional de desempenho previsto no art. 31 da Constituição do Estado e na Lei no 14.693, de 30 de julho de 2003;

$\mathrm{V}$ - vantagem pessoal de que trata o art. 49 da Lei $n^{\circ}$ 15.293, de 2004;

VI - vantagem temporária incorporável - VTI - prevista na Lei no 15.787, de 27 de outubro de 2005;

VII - parcela de complementação remuneratória do magistério PCRM - prevista no art. 4ํㅡㄹ da Lei no 17.006 , de 25 de setembro de 2007;

VIII - auxílio-transporte de que trata o art. 48 da Lei ํo 17.600 , de $1^{\circ}$ de julho de 2008;

IX - vantagem pessoal de que trata o $\S 4^{\circ}$ do art. $1^{\circ}$ da Lei $n^{\circ}$ 14.683 , de 30 de julho de 2003, bem como qualquer outra vantagem decorrente de apostilamento integral ou proporcional em cargo de provimento em comissão.

Segundo as entrevistadas, com o pagamento do subsídio, os professores não têm direitos de salário indireto como: serviço de transporte, creche, salário-família, vale alimentação, cesta básica de alimentos, auxílio estudo, vale transporte e auxílio creche. Os benefícios que os servidores públicos da educação recebem são o plano de saúde e assistência odontológica.

Segundo o sindicato, a política salarial adotada é a mesma para efetivos, efetivados e contratados, com os mesmos direitos e deveres para todas as categorias.

Quanto à intensificação do trabalho docente, o sindicato entende que essa intensificação ocorre devido ao acúmulo de trabalho em consonância com os baixos salários e a cobrança dos programas de controle de qualidade impostos pelo governo. Os professores veem-se obrigados a trabalhar em mais de uma escola para conseguirem manter um salário digno. As entrevistadas ressaltam que existe uma cobrança excessiva por parte do Estado com relação a resultados, e que o professor precisa trabalhar fora do horário de trabalho remunerado para conseguir cumprir com todas as obrigações que lhe são impostas- planejar aulas, elaborar e corrigir provas e estudar o conteúdo.

\section{Ação do SindUTE - Patos de Minas frente ao estado de Minas Gerais}

As entrevistadas foram questionadas sobre as ações que o SindUTE-Patos de Minas tem implementado frente ao governo do Estado de Minas Gerais. Foi colocado que as negociações que ocorrem entre sindicato e governo envolvem: regulação das formas de contratação, salários e benefícios trabalhistas, introdução de novas formas de organização do trabalho, implantação de novas tecnologias, valorização do profissional através de capacitações e melhorias no plano de saúde. 
Foi relatado que o principal mecanismo utilizado pelo sindicato são as greves, que são incentivadas quando falham as negociações com o Estado pelos direitos dos servidores estaduais da educação.

A greve ocorrida em junho 2011, em Minas Gerais, teve início em 08 de junho e duração de 112 dias. A principal reivindicação dos grevistas foi a valorização do profissional da educação, através da implementação do piso salarial nacional.

O sindicato foi questionado sobre o fato de as escolas estaduais de Patos de Minas não terem aderido à essa greve, e as entrevistadas $\mathrm{B}$ e $\mathrm{C}$ colocaram como principal motivo, a falta de mobilização por parte dos professores, falta de consciência política da classe.

Foi colocado que o SindUTE procura fazer essa mobilização através de um site constantemente atualizado, jornal mensal enviado a todos os sindicalizados, panfletos, reuniões e visita às escolas, mas que a concorrência com o Estado é desleal pois ele tem a mídia a seu favor.

As três entrevistadas argumentaram que o sindicato não tem condições financeiras de oferecer assistências e serviços aos sindicalizados, tais como: auxílio estudos, convênio creche, empréstimos, vale alimentação, seguro de vida, cesta básica de alimentos e plano de aposentadoria complementar. São oferecidos apenas convênio odontológico e assistência jurídica.

Percebe-se que o sindicato não apresenta uma ação política efetiva junto aos seus filiados, além de encontrar-se desmotivado e com uma postura defensiva. Um elemento que demonstra a pouca atuação política do sindicato foi o fato de nenhuma escola do município de Patos de Minas ter aderido à última greve dos professores de Minas Gerais. Nota-se que não estão sendo utilizadas estratégias eficazes de participação e politização por parte do SindUTE Patos de Minas frente aos professores envolvidos no processo.

\section{Considerações finais}

A presente pesquisa teve como foco as implicações das políticas públicas na reestruturação produtiva do mundo do trabalho dos professores na rede estadual de ensino do Estado de Minas Gerais, mais especificamente, da cidade de Patos de Minas/MG.

Para isso as reflexões levaram em consideração, sobretudo, as políticas públicas que orientam a reestruturação produtiva na esfera educacional e seus impactos no trabalho docente da rede pública estadual de Minas Gerais, a partir de 1990 quando se intensificam as reformas educacionais no Brasil e em Minas Gerais.

Para que os objetivos fossem alcançados, buscou-se problematizar a relação entre o mundo do trabalho e a educação, estabelecendo-se suas interfaces. O que mais chama atenção no debate atual sobre essa temática é que os professores passam por um crescente 
processo de desvalorização profissional, enquanto aumenta cada vez mais o nível de exigências frente ao mercado de trabalho.

Como questão principal, buscou-se compreender como o processo de reestruturação produtiva pelo qual o Estado vem passando desde as reformas educacionais dos anos 1990, tem impactado direta e indiretamente no trabalho do professor, dentro e fora da sala de aula. Através de alguns indicativos de resposta à presente questão foi possível verificar quais os processos de modificação pelos quais os profissionais da educação vêm passando para acompanhar a reestruturação produtiva na esfera educacional.

A questão da reestruturação produtiva se faz presente e necessita ser debatida no que se refere às mudanças nas condições dos trabalhadores envolvidos no processo de mundialização do capital.

A ordem social resultante da nova organização das relações capitalistas recai sobre os atendimentos públicos como a escola, de modo implacável, que causa o empobrecimento do trabalho docente.

O quadro de empobrecimento, deterioração social e as consequentes transformações nos modos de compreender a vida e o mundo, que se vive atualmente, de modo especial no Brasil e na América Latina, tem relação com a crise da escola, ou seja, com o abalo e o desmonte de um modo de atuar socialmente, desestabilizando seu funcionamento.

O desfecho da crise não parece que se dê na direção do fim da escola, peça indispensável no conjunto das medidas de convencimento e conformidade social à ordem estabelecida. Na luta em favor de transformações sociais, ainda que se acumulem denúncias e a busca por saídas, faz-se necessário reconhecer que a escola é fundamental como parte de um processo de civilização, cujas conquistas precisam ser preservadas.

O trabalho docente encontra-se inserido no contexto dessas transformações advindas do neoliberalismo. O aumento dos contratos temporários nas redes públicas de ensino, o arrocho salarial, o desrespeito a um piso salarial nacional, a inadequação ou mesmo ausência, em alguns casos, de planos de cargos e salários, a perda de garantias trabalhistas e previdenciárias vindas dos processos de reforma do Aparelho Estatal têm tornado cada vez mais agudo o quadro de instabilidade e precariedade do emprego no magistério público.

Foi realizada uma abordagem aprofundada sobre as reformas educacionais ocorridas nos anos 1990, com a promulgação da LDB 9394/96 que além de instituir a municipalização do ensino, aumentou as atribuições dos professores, nas quais os docentes passaram a se preocupar, além das questões relativas ao ensino-aprendizagem, com as atividades de gestão, planejamento, assistência e acompanhamento e integração escola-famíliacomunidade. Através dessa análise, foi possível perceber os indicativos do processo de precarização da função docente. 
Assim, conforme análises realizadas através dos dados da pesquisa, à luz do referencial teórico, pode-se inferir que os professores vem passando por um processo de desvalorização profissional, o que acarreta grande desmotivação por parte dos docentes.

No decorrer da pesquisa foi possível verificar que a intensificação do trabalho docente é confundida com maior profissionalismo, sentimento que é estrategicamente mobilizado pelas exigências oficiais de profissionalização do professor e pelo apelo a uma ética de autorresponsabilização moral e individual pelo sucesso da escola, como mecanismo fundamental nos novos moldes de gestão escolar.

Essas formas de gestão da conduta se deslocaram e ao mesmo tempo se combinam com formas mais tradicionais de controle do trabalho docente, como a supervisão direta no próprio local de trabalho e a demanda por trabalho burocrático para prestação de contas do ensino através dos processos de recentralização do poder estatal pela análise de resultados.

No decorrer da pesquisa, pôde-se verificar que a necessidade que o professor encontra de trabalhar em mais de uma escola para conseguir um salário digno é um fator preocupante para o SindUTE frente à atual conjuntura de trabalho docente.

Dessa forma, o sindicato demonstrou grande preocupação com os processos de precarização e intensificação do trabalho docente, principalmente com a desvalorização salarial - por meio do pagamento por subsídio e da forma de controle sobre o processo de trabalho- através da avaliação de desenvolvimento individual. Ficou claro que a fala das entrevistadas demonstra uma apatia e desânimo por parte do sindicato para lidar com as questões que envolvem o trabalho docente, sendo que o mesmo deveria atuar como uma liderança para os trabalhadores docentes.

Durante a entrevista com membros do SindUTE- Patos de Minas percebeu-se que não havia nenhum histórico no sindicato de pesquisas anteriores realizadas nas escolas estaduais de Patos de Minas sobre os impactos da reestruturação produtiva na educação nesse município.

Aponta-se então para a necessidade de aprofundamento nessas questões que podem servir de fonte para subsidiar programas e políticas voltados para a educação no Estado de Minas Gerais e para outros pesquisadores que se interessem por essa temática.

Sendo assim, a pesquisa teve sua hipótese corroborada, qual seja: os impactos trazidos pelas reformas educacionais dos anos 1990, com vistas às adaptações aos processos de reestruturação produtivas nos quais a educação está inserida.

\section{Agradecimentos}

À minha orientadora Professora Fabiane Santana Previtali, um exemplo de dedicação profissional, agradeço primeiramente pela confiança em acreditar no meu trabalho, 
encorajando-me nos momentos de encruzilhadas e incentivando a entrar cada vez mais no fascinante mundo da pesquisa. Obrigada pela clareza de suas explanações!

À todos os companheiros do Grupo de Pesquisa Trabalho Educação e Sociedade que compartilharam discussões e contribuíram bastante para o desenvolvimento deste trabalho.

Á diretoria do Sindicato Único dos Trabalhadores de Minas Gerais, regional Patos de Minas, pela atenção, cordialidade e por enriquecerem essa pesquisa.

À Capes, pelo incentivo por meio da bolsa concedida no período de março de 2010 a março de 2012.

\section{Referências}

AUGUSTO, Maria Helena Oliveira Gonçalves. Trabalho docente e organização escolar na rede estadual de ensino em Minas Gerais. 2004. 192 f. Dissertação (Mestrado em Educação) -FAE/UFMG, Belo Horizonte, 2004.

ALVES, Ana Carolina Timo. As reformas em Minas Gerais: Choque de gestão, avaliação de desempenho e alterações no trabalho docente. In: VI Seminário de Regulação Educacional e trabalho docente. Rio de Janeiro, 2006.

ARROYO, Miguel G. Trabalho-Educação e Teoria Pedagógica. In: FRIGOTTO (Org.) Educação e

Crise do Trabalho: perspectivas de Final de século. Petrópolis: Vozes, 2000.

AUGUSTO, Maria Helena Oliveira Gonçalves; MELO, Savana Diniz Gomes. A (des)valorização do magistério na rede pública estadual de Minas Gerais. In: Reunião Anual da ANPED, 27., Caxambu, nov. 2004. Anais...Caxambu, nov. 2004. Disponível em: <www.anped.org.br/reuniões/27/inicio.htm>. Acesso em: 9 jul. 2011.

BRASIL. Lei 11.788, de 25 de setembro de 2008. Disponível em: $<$ http://www.cvm.gov.br/export/sites/cvm/menu/acesso_informacao/servidores/estagios/3-

LEGISLACAO-DE-ESTAGIO.pdf>

MARQUES, Mara Rúbia Alves. Resenha. PEIXOTO, Maria do Carmo de Lacerda (Org.). Educação Superior: avaliação da produção científica. Belo Horizonte: Imprensa Universitária/UFMG, 2000, 293 p. Revista Brasileira de Educação, Autores Associados, n. 18, p. 148-149, 2001.

MINAS GERAIS. Lei n. ${ }^{\circ} 11.738$, de 16 de julho de 2008. In: Secretaria de estado da educação de Minas Gerais, 2011. Disponível em:< http://hera.almg.gov.br/cgi-bin/nphbrs?d=NJMG\&f=G\&l=20\&n=\&p=1\&r=1\&u=http://www.almg.gov.br/njmg/chama_pesquisa.as p\&SECT1 =IMAGE\&SECT2=THESOFF\&SECT3=PLUROFF\&SECT6=HITIMG\&SECT7=LINK ON\&SECT8=DIRINJMG\&SECT9=TODODOC\&co1=E\&CO2=E\&CO3=E\&co4=E\&s1=Lei\&s2=1 $8975 \& s 3=2010 \& s 4=\& s 5>$ Acesso em 30 out 2011. 
- Lei complementar no 71 , de 30 de julho de 2003. Disponível em: <http://www.ipsm.mg.gov.br/arquivos/legislacoes/legislacao/leis_complemetares/lei_comple mentar_71.pdf> Acesso em 25 junho 2011.

. Lei complementar no 100, de 05 de novembro de 2007. Disponível em: $<$ http://crv.educacao.mg.gov.br/aveonline40/banco objetos crv/\%7B01253DED-BFA3-46B0B2B1-24ABC0F16F83\%7D LEl\%20COMPLEMENTAR\%20100.pdf> Acesso em 25 junho 2011.

Decreto 44.559 de 29 de junho de 2007. Disponível em: <http://www.semad.mg.gov.br/images/stories/Flavia/decreto-44559-atualizado-agosto-

2010.pdf>

OLIVEIRA, Maria das Graças de. Condições de trabalho, gênero e saúde: sofrimento e estresse: um estudo de caso com os profissionais docentes do ensino superior privado de Belo Horizonte. Dissertação (Mestrado) - Pontifícia Universidade Católica de Minas Gerais, Belo Horizonte, 2002.

SANTOS, Jane Maria dos. O trabalho enquanto dimensão contraditória da potencialidade humana na trajetória de reestruturação produtiva, 2005. In:

Revista Urutágua. Quadrimestral - № 07 - Ago/Set/Out/Nov - Maringá - Paraná - Brasil ISSN 1519.6178. Disponível em: < http://www.urutagua.uem.br/007/07santos.pdf > Acesso em 22 jan 2010.

SINDICATO ÚNICO DOS TRABALHADORES EM EDUCAÇÃO DE MINAS GERAIS. Guia de convênio para filiados. Patos de Minas: SindUTE, 2006, $31 \mathrm{p}$.

VILHENA, Renata; SANTOS, Maria Taís. Gestão do gasto. In: VILHENA, Renata et al. 0 choque de gestão em Minas Gerais: políticas da gestão pública para o desenvolvimento. Belo Horizonte: Editora UFMG, 2006. 